\title{
NATIONAL PSYCHOLOGICAL FEATURES OF FOREIGN STUDENTS AND THE STYLE OF PEDAGOGICAL COMMUNICATION
}

\author{
I. Angelova* \\ Department of Medical Psychology and Foreign Languages, Faculty of Medicine, Trakia University, \\ Stara Zagora, Bulgaria
}

\begin{abstract}
The paper considers that the pedagogical communication in a foreign audience is a specific form of interaction between the subjects of intercultural communication a teacher and a student. It is formed on the basis of proficiency of the teacher of special communication technology, depends on his pedagogical mastery and is aimed at education, upbringing and development of the foreign students. It also has reserved for improving the educational process and developing the foundations of intercultural competence for both the student and the teacher. The author points out that the organization of professional pedagogical communication with foreign students requires the teacher to improve his psychological and pedagogical training and sufficient theoretical knowledge in the field of ethnopsychology and ethnopedagogy. The paper analyzes some of the most important national psychological features of the foreign students and their relation to the pedagogical communication.
\end{abstract}

Keywords: foreign students, national psychological features, communication skills, pedagogy.

\section{INTRODUCTION}

Universities have different content and technology of communication and yet the most important is communication for pedagogical purposes. In the field of education, communication is known as ,pedagogical communication" and is the subject of larger studies. For this reason, it is more clearly defined as a phenomenon than communications in scientific activity in the universities. The following factors are especially important for this type of human communication: social interaction, which connects people, forms groups and supports the development of communities; emotional experience as a result of some relationships between people; cognitive process of information exchange - perceptions, meanings, emotions, which lead to the dynamics of knowledge, orientations, attitudes and evaluations of the individual in the environment (1).

\footnotetext{
*Correspondence to: I. Angelova, Department of Medical Psychology and Foreign Languages, Faculty of Medicine, Trakia University - Stara Zagora, Bulgaria
}

Pedagogical communication between students and professors could be said to be an extremely complex phenomenon. The characteristics that identify it are exchange, transmission, interaction, connection, etc. From an informational point of view, when students and teachers communicate, there is a process of mutual exchange of different thoughts, feelings and experiences. The sociological approach focuses on the uniqueness of communication at the macro, meso and micro levels. At the macro level, communication is seen as an important part of a person's way of life, of his existence. At this level the problems of sociology and philosophy merge. The clear proof of such a thesis are the current conditions in Bulgaria (transition period for the economy, unemployment, competition, etc.), which make people strive for intensive career development, more guarantees for finding a job, for a wellpaid job, for mobility, etc. and all this is projected particularly brightly in the educational situation. It is important to note that communication should be seen as a factor in the development of social intelligence, 
which is increasingly becoming a goal of development, as it provides the building of interpersonal skills so that one can exist in the social world (2).

The multitude of relationships in the university environment is one of the most important features for building a sufficiently diverse arsenal of social skills and conditions for evaluation and self-evaluation of the results of social achievements, which in turn is a guarantee for the formation of social competence. Auditory and extracurricular contacts provide such opportunities, and here are of great importance those related to internships, internships, study trips and more. In this environment, both students and teachers reveal features and qualities in the field of their professional and personal characteristics, but also of their leading activities: teaching and learning.

The second level - the meso level - separate acts of communication are carried out, when the individual actually communicates with the others during joint activity. B. F. Lomov (3) believes that typical and traditional for the meso level is the problem of pedagogical tact, which is interpreted as a basis for proper relationships between teachers and students.

At the micro level, the individual elements of the act of communication are studied, playing the role of peculiar units. Such units are "question-question", interconnected facial expressions and others. The micro level is an immediate, real communicative activity in a specific communicative situation. The first two levels determine the strategy of communicative behavior of teachers and students, while the micro level determines and reveals the tactics of communicative behavior. Teaching experience shows that in building pedagogical communication there can be no small and insignificant things. Even the phonetic parameters of the teacher's speech (intonation, tone height, timbre of the voice) can be shocking and unacceptable for foreign students (4).

The teacher's voice should be calm - neither loud nor quiet; if students from the Asian region perceive the loud voice negatively, taking it for a shout, then the Arabs or Latin Americans with their lively temperament will get tired of the quiet and even voice of the teacher. To keep the attention of foreign listeners, the teacher's speech must be emotional. The diction of the pedagogue in a foreign audience needs to be as clear as possible, but not exaggerated, in order for the students to get used to the natural Bulgarian pronunciation. The teacher's facial expressions and gestures must be understood and accepted by the students, but this is not always an easy task, as in different cultures facial expressions and gestures have different and often opposite meanings. Therefore, the pedagogue must master the technology and technique of pedagogical communication, to use effectively verbal and nonverbal means and ways to influence the students.

No less important moment in pedagogical communication is the attitude to time. The founder of the theory of intercultural communication E. Hall divides cultures into monochrome and polychrome depending on the attitude of their representatives to time (5). For the most part, foreign students studying in Bulgaria belong to the polychrome cultures and do not know how to plan their study time precisely. It is difficult for them not to be late for classes, especially during the first months of training, because in their countries such behavior is not considered reprehensible. However, they cannot concentrate during the lesson, trying to do several things at once. It is also difficult for them to adequately perceive the time constraints to complete the given tasks or tests, because in their cultures the activity itself is important, not its time frames. When building pedagogical communication with foreign students, it is also very important to take into account the category of space, which is very different for different cultures. First of all, it is about the distance in communication, which is established depending on the age, gender, religion, social status of the participants in the communication. Some of the foreign students come to Bulgaria from Muslim countries, where it is difficult to contact a person belonging to another religion.

Examining the experience of teachers with long-term pedagogical activity, it is concluded that in many cases the teacher may be hindered by certain national stereotypes, such as the perception of students from Afghanistan, Turkey and some African countries as weak, poorly prepared in subjects, ignorant language mediator and ignorant of the realities of 
European life can be false: educated and English-speaking students have now begun to arrive in Bulgaria to study at universities. In other words, each of the experienced longterm teachers is faced with a similar change in stereotypes in their teaching. It is necessary for everyone to realize the stereotypes of their thinking, to be more attentive to the personality of the foreign student, which will help to avoid mistakes in pedagogical communication.

It is important to pay attention to such an interesting moment for teachers of intercultural communication as nationally determined ideas about the place and role of representatives of different sexes in different spheres of life. It is no secret that for many foreign students in their countries, the female teacher and the woman in general have quite different socio-role positioning (including gender-role, professional-role, etc.). Therefore, students must get used to the awareness of the importance of women in Bulgarian society and Bulgarian culture, which does not happen immediately.

The style of pedagogical communication plays an important role in teaching. A. V. Dobrovich believes that the teacher's style should be natural, but not formal (6). According to the definition of S. D. Smirnov, the style should carry the individuality of the teacher and be determined by the features of his personality (7).

The style of pedagogical communication with foreign students should be differentiated depending on the specifics of the specific situation. It is known that the educational traditions in China, Vietnam, Japan and other countries are associated with the image of the authoritarian teacher, which is why students from these countries find it difficult to get used to the friendly, democratic style of communication with Bulgarian teachers. African students are accustomed in their homeland to a "firmer" style of communication with the teacher. They may perceive the generally accepted style of communication in the audience in Bulgaria as frivolous. According to the model of communication of V. A. Kan-Kalik, it is desirable for communication to be based on dialogue or on the basis of joint activity (8).
ANGELOVA I.

Teachers with extensive practical experience know from their own experience how different the national patterns of behavior of students from different regions of the world are. This is why the classification of cultures used in the practice proposed by Richard Louise (9) is very convenient. According to its classification, depending on the way of organizing their activities, the cultures are divided into: monoactive (Germany, USA, UK, France and Sweden), polyactive (Spain, Italy, Latin America, Arab countries) and reactive (China, Vietnam, Korea and Japan).

The representatives of the monoactive cultures are oriented towards strict and punctual performance of the tasks. In disputes they are restrained, polite, try to be objective. Representatives of polyactive cultures are emotional, impulsive, verbose and not always punctual. They often change their plans, but in difficult situations they are able to improvise. The third group includes cultures whose representatives are silent, punctual, respectful to the interlocutor. It is considered that the first two groups (monoactive and polyactive cultures) are difficult to communicate with each other and easier with the representatives of reactive cultures.

In an international environment, intercultural communication takes place in the process of interaction not only between representatives of one culture and representatives of other cultures but also in the interaction of foreigners with the teacher who is the bearer of the culture of the country. In the process of communicating with students, it is important to take into account both their value orientation and the specifics of the national mentality. We can talk about the peculiarity of the process of communication between representatives of different cultures. Emotional Arabs or Latin Americans and the seemingly unperturbed peoples of Southeast Asia may experience equally strong feelings, but their manifestations may be different. Therefore, on the one hand, in his work the teacher must be guided by the knowledge of the peculiarities of communication between representatives of different nations, on the other hand to accustom them to tolerance in their relations with each other, and on the third - to educate students in communicatively behavior towards native speakers of the language studied. 
ANGELOVA I.

Of course, the teacher working with foreigners must have an idea of the style and motives of the behavior of his students. He also needs to know which and with which of the three listed categories of cultures will communicate more easily. For example, students from China, Vietnam, Korea, and Japan (as residents of countries with a reactive culture of behavior) adapt to other nations more easily. The ideas about the style and motives of the students' behavior will help, on the one hand, to avoid conflict situations between the representatives of different cultures, and on the other hand - to prevent the teacher from making mistakes in the process of pedagogical communication. It is known from practice that many teachers prefer to work with a certain contingent of students. It is possible that their personal characteristics make it easier for them to perceive the representatives of this culture and to accept the given manner of behavior more easily.

Along with the difficulties that students face in a foreign country, along with the often painful adaptation, they also experience difficulties with the collision with other cultures and the mentality of their colleagues. The knowledge of the national psychological peculiarities of the foreign students will allow us to determine the parameters of the pedagogical communication with the representatives of the different cultures and to offer to the teachers' recommendations for organization of the intercultural communication.

Thus, pedagogical communication in a foreign audience is a specific form of interaction between the subjects of intercultural communication, teacher and student. It is formed on the basis of the teacher's mastery of special communication technology, depends on his pedagogical skills, and is aimed at education, upbringing and development of the foreign student. It also has reserved for improving the educational process and developing the basics of the intercultural competence of both the student and the teacher. The organization of professional and pedagogical communication with foreign students requires from the teacher improvement of his psychological and pedagogical training and sufficient theoretical knowledge in the field of ethnopsychology and ethnopedagogy.
Due to the fact that the modern university is a multicultural space in which there is a dialogue between representatives of different cultures, university teachers must master the organization of interethnic and intercultural communication. Pedagogical communication between university professors and foreign students has all the basic characteristics of communication: interaction between the subjects of communication (in this case - a teacher and a foreign student), socio-cultural nature of communication, its functionality. The structural element of communication is the communicative act, and its functional unit - the communicative task. Pedagogical communication in this case is a socio-role pedagogical interaction, which is aimed at forming skills and habits for intercultural communication, respectively; it must be inscribed in appropriate organizational and didactic forms.

Thus, although the problem of the interaction between lecturer and student at the university is in the process of intensive scientific reflection and analysis and is far from being solved, its huge potential from a research point of view leaves no doubt. The end result of the students' education must be achieved by solving the daily, constantly changing educational tasks facing the teacher. At the same time, it is important to define both the near and the distant tasks for the development of each student of his important professional qualities and for his upbringing as a person. It is known that the formation of a person's personality takes place throughout his life, but it is in the university that the foundations are laid for those qualities of the specialist, with which he will then enter his new field of activity and in which his further development as a person will take place.

\section{CONCLUSION}

As student age is a time for personal and professional self-determination, the period of study at the university under the professional guidance of the teacher should be aimed at developing in each student a high intellectual, spiritual, physical and cultural level of personality and build in his ability to live in civil society. The main means of influencing the pedagogue is himself as a person, and not only as a qualified specialist with the necessary set of knowledge and skills has (the profession of pedagogue required constant 
improvement of personality, development of interests, abilities). It is the human qualities that he possesses that play a decisive role in the effective work of the teacher. And when they are further reinforced by appropriate didactic techniques and tools, skilfully used in the training, an extremely impressive synergy effect can be expected.

\section{REFERENCES}

1. Lasuel, H., Shram, U., de Flyor, M., Robarts, D., Makkueyl, D., Komunikatsiyata, Universitetsko izdatelstvo "Sv. Kliment Ohridski”, S.,1992.

2. Aleksandrov, P., Intelekt i obuchenie, S., 1990.

3. Lomov, B., F., Sistemnosty $\mathrm{v}$ psihologii: izbrannie psihologicheskie trudui / B.F. Lomov. - M.: MPSI, s. 424, 2011. (Psihologi Rossii). ISBN 978-5-89502-522-2.
ANGELOVA I.

4. Ter-Minasova, S., G., Yazuik i mezhkulyturnaya kommunikatsia. - M., s.22, 2000.

5. Hall, E., The Silent Language., N.Y.;L., 1990.

6. Dobrovich, A., V., Obshtenie: nauka i iskusstvo. M.: Znanie, 1978.

7. Smirnov, S., D., Pedagogika i psihologia vuisshego obrazovania: ot deyatelynosti $\mathrm{k}$ lichnosti: ucheb.posobie dlya stud. vuissh. ped. uchebn. Zavedeniy - M.: Akademia, 2003.

8. Kan-Kalik, V., A., Osnovui professionalynopedagogicheskogo obshtenia,.- Groznuiy: GPI, 1979.

9. Lyyuis, R., Delovuie kulyturui v mezhdunarodnom biznese. Ot stolknovenia $\mathrm{k}$ vzaimoponimaniyu, per. s angl. - 2-e izd. M.: Delo, s. 64 - 76, 2001. 
ANGELOVA I. 